\title{
Galathea-3: A global marine gravity profile
}

Strykowski, Gabriel; Cordua, Knud Skou; Forsberg, René; Olesen, Arne Vestergaard; Andersen, Ole Baltazar

Published in:

International Association of Geodesy Symposia

Link to article, DOI:

10.1007/978-3-642-20338-1_44

Publication date:

2012

Link back to DTU Orbit

Citation (APA):

Strykowski, G., Cordua, K. S., Forsberg, R., Olesen, A. V., \& Andersen, O. B. (2012). Galathea-3: A global marine gravity profile. International Association of Geodesy Symposia, 136, 365-371.

https://doi.org/10.1007/978-3-642-20338-1_44

\section{General rights}

Copyright and moral rights for the publications made accessible in the public portal are retained by the authors and/or other copyright owners and it is a condition of accessing publications that users recognise and abide by the legal requirements associated with these rights.

- Users may download and print one copy of any publication from the public portal for the purpose of private study or research.

- You may not further distribute the material or use it for any profit-making activity or commercial gain

- You may freely distribute the URL identifying the publication in the public portal

If you believe that this document breaches copyright please contact us providing details, and we will remove access to the work immediately and investigate your claim. 


\title{
Galathea-3: A global marine gravity profile
}

\author{
G. Strykowski, K.S. Cordua, R. Forsberg, A.V. Olesen and O.B. Andersen \\ DTU Space, National Space Institute, The Technical University of Denmark, Juliane Maries Vej 30, DK-2100 \\ Copenhagen Ø, Denmark, Email: gs@space.dtu.dk
}

\begin{abstract}
Between Aug 14, 2006 and Apr 24, 2007, and enjoying a considerable interest from the Danish authorities, the Danish public and the Danish media, the scientific expedition Galathea-3 circumnavigated the globe. Its domestic purpose was to attract the Danish youth to science.

DTU Space, Technical University of Denmark, participated in the expedition with two experiments. From Perth, Western Australia to Copenhagen, Denmark the exact position and movements of the ship were monitored using a combination of GPS, INS and laser measurements. The purpose was to measure the instantaneous sea surface topography.

This paper reports on the second experiment in which a continuous marine gravity profile along the ship's route was measured. The focus of the paper is on the practical aspects of such large scale world wide operation and on the challenges of the data processing. Furthermore, the processed free-air gravity values are compared to 3 global models: EGM96, EGM08 and DNSC08. Even though the along-track resolution of marine data is higher than the resolution in any global gravity model (which influences the direct comparison of the collected marine data to the model) the statistics for the residual free-air gravity anomalies show, that EGM08 and DNSC08 are better models than EGM96 for all Galathea-3 legs. Some areas along the ships route are quite challenging for modellers.
\end{abstract}

Keywords:

Marine gravity, harbour ties, Eötvos correction

\section{Introduction}

Between Aug 14, 2006 and Apr 24, 2007, the Danish Galathea-3 expedition circumnavigated the globe by sailing more than $60.000 \mathrm{~km}$, see Fig 1 . This was the largest Danish scientific expedition in more than 50 years following two great expeditions of the past; Galathea-1 (1845-1847) and Galathea-2 (1950-1952). The overall political aim was to attract the Danish youth to the natural sciences.

The scientific part of Galathea-3 consisted in total of 71 projects on board the navy surveillance vessel Vcedderen ('The Ram') which was modified for the expedition. There were some 35 scientists on-board, a dozen of journalists, photographers and TV crew members, two high-school students and a teacher, and a crew of 50 from The Royal Danish Navy ${ }^{1}$.

DTU Space participated in the Galathea-3 expedition from Perth, Western Australia to Copenhagen, Denmark measuring gravity and sea level heights along the ship's route. The results of sea level height measurements using GPS, INS and laser were reported by Andersen et al. (2009).

The gravity anomaly variations along the route mainly reflect the changes of the depth to the sea bottom. These depths are not always well known in parts of the world's oceans; e.g. in the southern Pacific Ocean. In an independent Galathea-3 project the Danish Hydrographic Office charted the depths to the sea bottom and made the raw depth data available to the gravity project

The timing of the Galathea-3 expedition was just prior to the release of the new global Earth gravity model EGM08 (Pavlis et al, 2008) and the associated background products. One such product is DNSC08 (Andersen and Knudsen, 2008); a global gravity model from satellite altimetry for the marine areas which also includes a high resolution global bathymetry/topography model.

Figure 1 shows that the ship's route, e.g. in South America, is in near coastal areas; i.e. an area which is particularly challenging in constructing the global gravity models. Consequently, such direct and independent measurements of gravity can serve as a valuable validation tool for the global models.

Another possible use of such long marine gravity profiles is the possibility to validate the old marine gravity survey data. Usually, the data from each marine survey are processed independently and linked to some known reference gravity value on land through a harbor tie. If this reference gravity value is wrong or uncertain, or if the data processing is wrong, the whole gravity survey is biased or tilted. By crossing the old marine surveys with a consistent and modern marine survey, the relative biases of the old marine surveys with respect to each other can be detected.

\footnotetext{
1 Web 1: http://www.galathea3.dk/uk
} 
Section 2 contains a short description of the setup of the gravity system on-board Galathea-3. The semi-automatic procedure for the data collection and the handling of the data gaps in both gravity and GPS data are briefly described in section 3. In section 4 we shortly report on the harbor ties. In particular, we mention the practical aspects of collecting such measurements in remote parts of the world. Section 5 discusses the importance of the ship's navigation, which in case of Galathea-3 expedition was not optimal. In section 6 we briefly describe the changes in the marine gravity software that were implemented. In section 7 we compare the results of the gravity data processing to 3 global gravity models: EGM96, EGM08 and DNSC08.

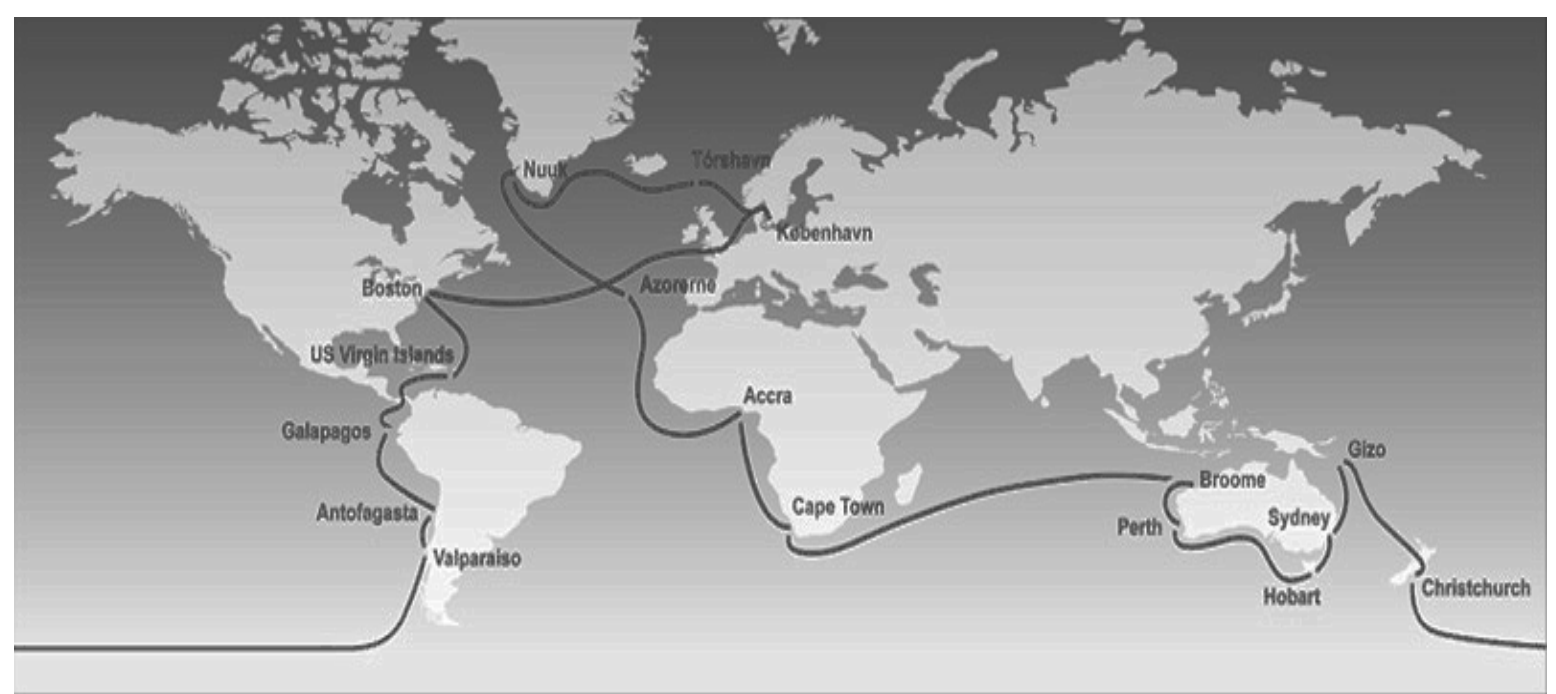

Figure 1. The Galathea-3 route from Copenhagen and around the world.

\section{Gravity measurements - the setup}

The Technical University of Denmark, DTU Space, The National Space Institute, participated in the Galathea-3 expedition with a gravity project. From Perth, Western Australia to Copenhagen, Denmark a ZLS Ultrasys LaCoste \& Romberg (LC\&R) SeaAir gravimeter, S-38 (a long-term loan from NGA, USA) was operated. It resulted in an almost continuous (see section 3) marine gravity transect from the southern to the northern hemisphere. The meter occupied a small area, see Figure 2, in the corner of "the hangar" on the main deck, i.e. a place where the helicopter could be stored when the vessel was operating as a naval surveillance ship. During the Galathea-3 expedition, the vessel was modified to accommodate the research facilities and "the hangar" was used as a meeting and lecture area. Horizontally, the gravimeter was placed as close as possible to the location of the centre of mass (CM) of the ship. Vertically, the gravimeter was on the main deck, i.e. above the CM of the vessel. Other locations were considered, but the placing of the meter closer to the $\mathrm{CM}$ in the vertical was not practical.
Even though the navigation of the ship was constantly monitored by the central GPS antenna a set of two independent Javad antennas were placed on the roof of the bridge (see Figure 3 ). The signal from the GPS antennas was collected on the bridge and merged with the bathymetric signal provided by The Danish Hydrographic Office, see section 1.

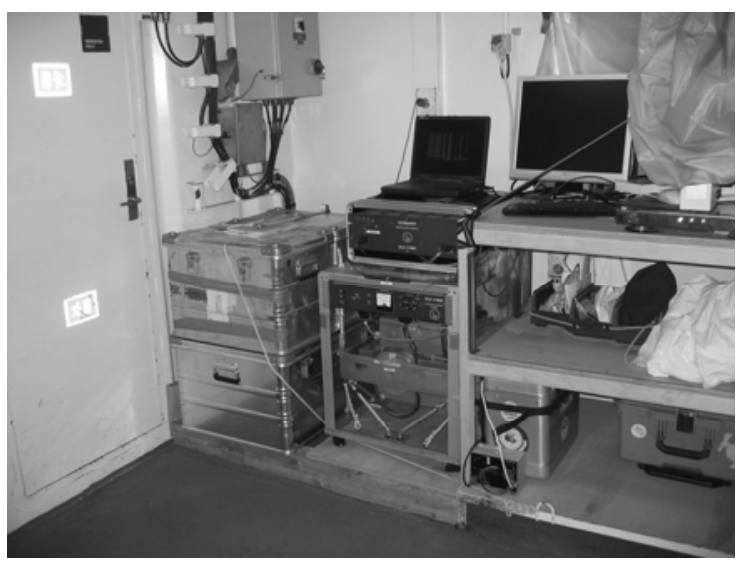

Figure 2.The LC\&R S-38 marine gravity meter in "the hangar". The LC\&R land gravity meter G-867, which was used for the harbour ties, is stored in an aluminium box and strapped to the lower shelf next to the marine meter. 


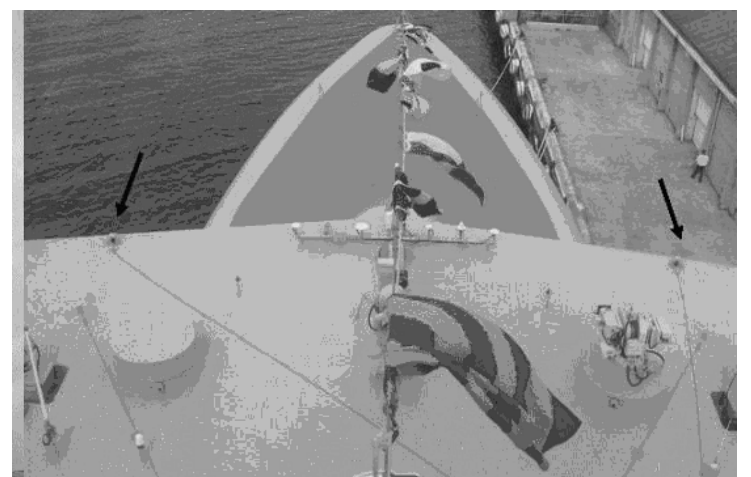

Figure 3.Two Javad GPS antennas (indicated by arrows) were installed on the roof of the bridge.

\section{The data collection and the data gaps}

The logistics of the expedition and various scientific projects on-board were organized in legs, i.e. in parts of the route between two harbour stays. A project span could be one or more of such legs. It is during the short and busy harbour stays that the crew could be replaced, the new project scientists could enter the vessel and the old projects could disembark. Any delay could affect other projects.

It is under these conditions that the hardware for the two DTU Space projects was mounted in Fremantle, Western Australia. It took some time to make the system work and to do the harbour tie. Although prior to the Galathea-3 expedition there was a trial cruise in Denmark where the equipment could be tested, not everything could be planned ahead. Under such strict time constraints it required skill and a lot of experience to install the hardware and to solve the data collection problems.

Concerning the gravity project, the gravimeter data and the navigation/bathymetry data were collected separately. The time stamp for the gravimeter data was the UTC time while for the navigation and bathymetry data it was the GPS time. There was at the time of expedition a time difference of $14 \mathrm{sec}$ between the two clocks. Furthermore, there is a time delay between the timing of the individual gravity measurements and the timing of their output as an averaged gravity value, see section 6 . The requirement was to take all the above into consideration when e.g. deciding on the sampling rate for the data collection.

Ideally, for both DTU Space Galathea-3 projects, the data collection was semi-automatic, i.e. the data could be collected without the presence of DTU Space personnel. During the short harbour stay the system could be switched on and off, a harbour gravity tie could be made (see section 4 ) and the data from the finished leg could be downloaded and stored. Thus, unlike for most other Galathea-3 projects, the main working load for the DTU Space projects was in the harbours. In practice, the DTU space personnel boarded the vessel roughly every second leg. For the "unmanned" survey legs the colleagues from The Danish Hydrographic Office were trained to download the data and to manage the switching off and restarting the system. In case of problems they could communicate by email with the trained personnel from DTU Space.

Despite all these efforts to ensure the continuity in the data collection in a semi-automatic mode, there were problems in running the system with untrained surveillance which, unfortunately, led to some undesirable data gaps, see below.

In the survey leg from Fremantle, Australia to Hobart, Australia, there is a data gap in the first part of the leg caused by the limited installation time in Fremantle. On leaving the harbour, the ad-hoc navigation collection system was not yet fully operational. Fortunately, the marine gravimeter was running all the time. For the "unmanned" leg between Sydney, Australia and Gizo, The Solomon Islands, the gravimeter was not collecting data at all. The software stopped collecting the data shortly after leaving the Sydney harbour without anybody noticing it. For the leg along Antarctica in the southern Pacific Ocean, and without the presence of DTU Space personnel, the gravimeter was clamped in the Argentinean territorial waters, because the expedition had no formal permission to collect data there. Crossing the Gulf Stream on a leg from St. Croix, The West Indies to Boston, USA, and without any DTU Space personnel on-board, the data were not collected. Crossing the Atlantic, from Boston, USA to Copenhagen, Denmark the gravimeter was switched off by accident.

Furthermore, there were frequently drop outs in the collection of GPS data and in merging the depth data. In fact, the DTU Space staff when present frequently checked whether the GPS collection system and the merging with the depth data were running as expected. Consequently, a successful semi-automatic data collection certainly requires a more stable data collection system and, perhaps, more time for the installation. Also, the presence of trained personnel is desirable.

The standard sampling rate for the gravimeter was 10s, except in the West Indies; between the islands of St. Croix and St. Thomas where it was 1 sec. The sampling rate in the West Indies was denser because the gravity data could support a high-resolution seismic project there. 


\section{The harbour ties}

One important aspect of a marine gravity survey are the harbour ties, i.e. a calibration measurement which relates the marine gravimeter reading (in counter units, CU) to the absolute gravity value transferred from a known gravity station on shore. For a gravity survey circumnavigating the globe, such measurements are particularly challenging. They are difficult (if not impossible) without the help from the local authorities and local colleagues. To ensure the harbour ties along Galathea- 3 route DTU Space has contacted a number of national and international institutions (Geoscience Australia (formerly AGSO); LINZ, New Zealand; Instituto Geográfico Militar, Chile) and few individuals who coordinate large scale gravity data collection (Steve Kenyon, NGA, USA; Denizar Blitzkow, Univ. São Paulo, Brazil). With their help, the harbour ties could be measured in such remote places as the Solomon Islands and the Galapagos Islands.

The harbour ties were constrained in time to the short harbour stay, see section 2. A DTU Space LC\&R land gravity meter G-867, see Figure 2, was used. The meter was permanently stationed on the vessel for the duration of the Galathea-3 expedition.

In Chile the measuring of the harbour ties was quite easy, but the high quality gravity stations in Valparaiso and Antofagasta were inside the military areas. Thus, in order to measure there a special permission was needed, which was facilitated by the Instituto Geográfico Militar. Other places it was sometime unclear whether permission was needed and how to obtain it. In the Galapagos Islands a colleague from DTU Space almost got arrested for making a harbour tie without a formal permission.

In Gizo, The Solomon Islands, the situation was also difficult, but mostly from the technical point of view. Firstly, the vessel was not anchored at the harbour but in the middle of a bay. Secondly, the reference land gravity station for a harbour tie was on a neighbouring island. It took 2 days to transfer the gravity value to both sides of the bay. A simple interpolation technique based on distance weighting to the two stations was used to make a harbour tie.

\section{The navigation}

The modern marine gravity surveys are often conducted in connection with seismic surveys. The advantage is, that the marine seismic survey navigates in "straight lines" (i.e. in sections with a constant azimuth) and at a constant and moderate speed. This type of navigation is optimal for the gravity surveys because the Eötvos correction (see e.g. Torge, 1989, Eq. 7-21a) is constant.

The navigation of Galathea-3 expedition was mainly governed by the needs of other projects; i.e. holding still for taking samples of the sea bottom or sea water, or for fishing. At other times the vessel speeded up to catch up with the time delay.

Another characteristic of Galathea-3 navigation was that there were no crossings points, i.e. that the vessel return to the same location at some later time. In marine surveys where gravity and seismic data are collected there is usually a substantial number of crossing line segments. The advantage of such configuration is that it provides a more robust estimation of the linear drift model for the marine gravimeter. If no such crossing points are available, the estimation of the drift model is based solely on the harbor ties corrected for the tidal signal.

As stated in section 2, in the Galathea-3 experiment two GPS antennas were mounted on the roof of the bridge of the vessel to yield an independent system. The antennas were mounted to the port side and the star side of the ship and placed such that no objects on the ship could shade for the antennas, see Figure 3. This antenna configuration was more relevant for the sea surface topography project than for the gravity project. The idea was to monitor not only the movement of the centre of mass of the vessel, but also the tilt, roll and yaw of the ship and to correct for the deviation of the laser beam from the verticality (Andersen et al., 2009).

In practice, for the Galathea-3 gravity project, and after some experiments in harbours, we found it redundant to use the star side antenna as it doubled the amount of input data without improving the gravity and sea surface topography information.

\section{The data processing}

The challenge of the Galathea-3 expedition forced us to revise the software previously used e.g. in processing survey data from Greenland and around the Faroe Islands. The main difference is that data previously had to be organized in line segments associated with "the seismic lines". Each segment was individually inspected, corrected and went into the adjustment. The processing was quite laborious.

Such a procedure was not applicable in the present case. The whole survey is just one long line, often without any crossing points, and stretching in time over many days. In the software bookkeeping we use Julian days, JD, for the time sequence, and, thus, precisely like in the standard Ultrasys LC\&R data format for the raw gravimeter readings. The 
new software uses as input all the marine gravity data in one file ordered by the (UTC) time and the navigation/depth data in another file ordered by the (GPS) time. Also, for each survey leg, the harbour ties are input into the software in a separate file. The software output is a file with all the processed marine gravity data for each survey leg. The new software can also process marine data from the old type of survey based on seismic lines (see above).

The time difference between the two clocks (GPS and UTC, see section 3) is handled by a time shift and the large data gaps in both the gravity and the GPS navigation data are identified. The gap in the GPS navigation data, while the gravimeter is still running, is not that serious. One can still assume the same instrumental drift model for the marine gravimeter across the gap. Due to the lack of the navigation data (i.e. the positions for the gravity stations) there will be no output data for this part of the survey, but the continuity of the gravity data across the gap is valid. One additional, problem is that the GPS navigation data are also used for modelling the Eötvos correction (see below) filtered consistently with the gravity and bathymetry data. It takes few initial healthy GPS data before the filtered Eötvos corrections can be used.

More severe problems with data gaps are the gravimeter malfunction at sea, see section 3 . This violates the continuity in the gravity data collection and breaks the implicit assumption of a constant linear gravimeter drift between the harbours. The problem can to some degree be overcome (bias and tilt correction) using a comparison with the existing knowledge about other gravity in the area. The problem is similar to the problem of ensuring the results of a marine survey even when one or two harbour ties are missing. The drawback is that the survey results and the other existing gravity data from the area are no longer independent.

After the data gaps were identified, the remaining healthy navigation and depth data were interpolated to the (UTC) timing of the marine data leading to a consistent data set: time, location, depth (if available), gravity reading. Subsequently, the navigation data and the time were used to model the fictitious accelerations affecting the gravimeter reading (the Eötvos correction, see Torge 1989).

One difficulty is that the standard Ultrasys output gravity data are averages in time so that the timing of the gravity output does not reflect the gravity reading for this navigation position but is an averaged value for prior positions. Thus, the output gravity data must be shifted backward in time to the correct location and the Eötvos correction must be filtered consistently. The filtering is done by a sequence of digital filters. The depth data, if known, must be filtered accordingly to yield the Bouguer anomaly. If the depth data are available the output is the free-air anomalies and Bouguer anomalies, if not, only free-air gravity anomalies are output.

The Galathea-3 navigation data included raw depth records provided by The Danish Hydrological Office. The data transfer was sometimes unstable and the data themselves were often very noisy. A preparation of such data for the Bouguer gravity processing requires a cumbersome data cleaning the removal of the spikes, the smoothing, and often the interpolation. At the present, it was only done to the data from the leg between St Thomas and St Croix in the West Indies. We found it useful to use the global bathymetry models, e.g. DNSC08 (Andersen et al., 2008), as a reference. Especially when there was a doubt of which of the different (and shifted in the vertical) pieces of the raw depth information was correct. The Danish Hydrological Office in their project will provide a clean set of depth data.

In practice, in the new software, there are some limitations to the size of the input data files. The processed Galathea-3 gravity data were processed leg by leg, and for some legs even split into smaller units (related to the data gaps). The data sampling was the standard $10 \mathrm{sec}$, except for the St Thomas St Croix leg when it was 1 sec.

\section{Comparison with the global models.}

The Galathea-3 free-air gravity anomalies were compared to 3 global gravity models (GM): EGM96 (Lemoine et al., 1998), EGM08 (Pavlis et al., 2008) and DNSC08 (Andersen et al., 2008a, 2008b). For practical reasons, i.e. because the number of data is quite large (1261833), we've computed GM gravity values using a dense grid (spacing NSxWE: $0.025^{\circ} \times 0.025^{\circ}$ ) for each survey leg. For each GM we used the maximal truncation degree $\mathrm{N}_{\max }$ (EGM96: $\mathrm{N}_{\max }=360$; EGM08: $\mathrm{N}_{\max }=2160$ ). The model values $\Delta g_{G M}$ were then interpolated from grids to the location of the gravity data $\Delta g$ and subtracted. Table 1 shows the residual statistics for $\Delta g_{\text {res }}$, where $\Delta g_{\text {res }} \equiv \Delta g-\Delta g_{G M}$.

The marine data have a higher along-line spatial resolution than any GM. If the gravity field in some area varies a lot large values of min and max for the residuals can be expected. The GMs are by default too coarse to model such details. However, the GMs themselves, e.g. EGM96 vs. EGM08 or DNSC08, can also differ. This is clearly seen in e.g. the St Thomas-St Croix leg, a relatively small area where the EGM96 residual statistics are extremely bad, 
while the EGM08 and DNSC08 statistics look fine and consistent with Galathea-3 data. Thus, for this area EGM08 and DNSC08 improve the gravity information compared to EGM96 and Galathea-3 marine data confirm this independently.

In general, the residual statistics are better for survey legs when DTU Space personnel were on- board. This could be improved in the future by providing a more robust data collection system.

The Galathea-3 marine data are now ready for a detailed inspection, and will in the near future be enhanced with the depth information provided by the Danish Hydrographic Office so that the Bouguer gravity anomalies can also be computed.

Table 1. Statistics of the residual free-air gravity anomalies (in mgals) for each Galathea-3 survey leg.

\begin{tabular}{|c|c|c|c|c|c|c|c|c|c|c|c|c|c|}
\hline & \multicolumn{4}{|c|}{$\begin{array}{llll}\text { DNSC08 } & & \\
\text { Mean } & \text { Std. } & \text { Min } & \text { Max }\end{array}$} & \multicolumn{4}{|c|}{ EGM08 } & \multicolumn{4}{|l|}{ EGM96 } \\
\hline \multirow[t]{2}{*}{ Perth-Hobart } & $\Delta g_{G M}$ & -10.8 & 26.9 & -100.5 & 62.1 & -10.7 & 26.8 & -99.6 & 63.6 & -8.3 & 20.2 & -96.2 & 42.6 \\
\hline & $\Delta g_{\text {res }}$ & 1.1 & 7.7 & -51.7 & 66.3 & 1.0 & 7.8 & -53.2 & 66.2 & -1.4 & 18.0 & -56.7 & 81.2 \\
\hline \multirow[t]{2}{*}{ Hobart-Sydney } & $\Delta g_{G M}$ & -16.0 & 36.9 & $\begin{array}{l}-92.9 \\
\end{array}$ & 52.5 & -16.2 & 36.7 & -91.7 & 52.7 & -13.2 & 37.8 & $\begin{array}{l}-76.3 \\
\end{array}$ & 48.2 \\
\hline & $\Delta g_{\text {res }}$ & 0.9 & 6.5 & -31.1 & 37.6 & 1.1 & 6.5 & -30.5 & 35.3 & -2.0 & 14.5 & -46.0 & 31.4 \\
\hline Sydney-Gizo & & \multicolumn{4}{|c|}{ No data } & \multicolumn{4}{|c|}{ No data } & \multicolumn{4}{|c|}{ No data } \\
\hline \multicolumn{2}{|c|}{ Gizo-Christchurch $\Delta g_{G M}$} & 11.1 & 37.2 & -104.4 & 157.1 & 11.4 & 37.1 & -85.2 & 154.9 & 9.6 & 24.9 & -51.2 & 95.4 \\
\hline & $\Delta g_{\text {res }}$ & 1.3 & 10.4 & -60.7 & 190.6 & 1.1 & 10.1 & -61.9 & 187.9 & 2.8 & 25.5 & -70.8 & 151.7 \\
\hline Christchurch- & $\Delta g_{G M}$ & 7.7 & 31.5 & -100.9 & 116.0 & 8.7 & 32.2 & -101.2 & 117.8 & 7.6 & 26.4 & -88.8 & 76.3 \\
\hline Valparaiso & $\Delta g_{\text {res }}$ & -10.4 & 20.9 & -96.0 & 89.0 & -11.4 & 22.3 & -99.6 & 88.3 & -10.3 & 24.8 & -120.2 & 103.4 \\
\hline Valparaiso- & $\Delta g_{G M}$ & -59.5 & 75.0 & -178.0 & 75.8 & -59.3 & 75.0 & -177.5 & 75.8 & -61.4 & 78.9 & -172.5 & 93.3 \\
\hline Antofagasta & $\Delta g_{\text {res }}$ & -5.6 & 7.9 & -49.7 & 53.8 & -5.7 & 7.8 & -50.4 & 43.9 & -3.7 & 23.2 & -101.3 & 53.5 \\
\hline Antofagasta- & $\Delta g_{G M}$ & -45.3 & 54.8 & -248.8 & 86.2 & -45.3 & 54.9 & -247.9 & 84.8 & -48.4 & 49.6 & -211.1 & 94.2 \\
\hline Galapagos & $\Delta g_{\text {res }}$ & 0.2 & 8.3 & -60.9 & 70.1 & 0.1 & 8.3 & -60.0 & 69.7 & 3.3 & 21.7 & -103.6 & 90.0 \\
\hline Galapagos- & $\Delta g_{G M}$ & 9.0 & 41.9 & -155.7 & 130.8 & 9.6 & 42.6 & -156.0 & 129.8 & 10.9 & 38.4 & -98.1 & 112.2 \\
\hline St. Thomas & $\Delta g_{\text {res }}$ & 1.7 & 8.4 & -133.3 & 129.9 & 1.1 & 8.6 & -133.1 & 129.8 & -0.2 & 24.0 & -181.8 & 124.3 \\
\hline St Thomas- & $\Delta g_{G M}$ & -30.7 & 80.2 & -171.9 & 111.0 & -31.0 & 80.2 & -174.1 & 109.4 & 20.6 & 20.8 & -26.0 & 69.2 \\
\hline St Croix & $\Delta g_{\text {res }}$ & -0.2 & 12.6 & -50.3 & 55.7 & 0.0 & 13.5 & -52.8 & 58.2 & -51.6 & 83.8 & -184.5 & 143.9 \\
\hline St Croix - & $\Delta g_{G M}$ & -25.9 & 20.0 & -199.0 & 57.2 & -25.7 & 20.1 & -199.6 & 59.0 & -25.3 & 19.3 & -201.0 & 22.6 \\
\hline Boston & $\Delta g_{\text {res }}$ & -0.1 & 7.2 & -67.2 & 128.7 & -0.2 & 7.2 & -65.6 & 127.9 & -0.6 & $12.6^{\prime}$ & -86.3 & 123.1 \\
\hline Boston- & $\Delta g_{G M}$ & 13.9 & 24.7 & -66.1 & 134.6 & 13.9 & 24.5 & -64.2 & 131.5 & 14.0 & 21.8 & -63.2 & 76.4 \\
\hline Copenhagen & $\Delta g_{\text {res }}$ & 0.3 & 5.1 & -35.2 & 48.7 & 0.3 & 5.1 & -36.0 & 50.4 & 0.2 & 13.1 & -49.2 & 110.7 \\
\hline
\end{tabular}

\section{Conclusions}

In this paper we report on the practical aspects of collecting a very long marine gravity transect on a global scale, and the subsequent data processing. The navigation of the Galathea-3 expedition was not optimal for the gravity data collection. Nevertheless, useful gravity information was collected and processed. The measured data cross many interesting and challenging areas for the global gravity models and the processed data can be used as a valuable verification tool.

Acknowledgements Dansk Expeditionsfond for including DTU Space's “Tyngdeprojektet” as a part of Galathea-3 expedition. This is an official Galathea-3 publication P51.

\section{References}

Andersen, O. B., and P.Knudsen (2008a), The DNSC08 Mean Sea Surface and Mean Dynamic Topography, J. Geophys. Res (Submitted).

Andersen O. B., et al. (2008b), The DNSC08 global Mean sea surface and Bathymetry. EGU-2008, Vienna, Austria, April.

Andersen, O B, A.V. Olesen, R. Forsberg, G. Strykowski, K. Cordua and X. Zhang (2009), Ocean Dynamic Topography from GPS - Galathea-3 First results. Proc. GGEO2008 symposium, Crete, Springer Verlag, in print.

Lemoine et. al (1998) The development of the Joint NASA GSFC and the National Imagery and Mapping Agency (NIMA) Geopotential Model EGM96, NASA/TP-1998206861.

Pavlis, N. K: S. Holmes, S. C. Kenyon and J. K. Factor (2008), An Earth Gravitational model to degree and order 2160: EGM2008, presented EGU, Vienna, April.

Torge, W. (1989), Gravimetry, de Gruyter. 